$11-16-2020$

\title{
An Agent-based Simulator for the Gastrointestinal Pathway of Listeria monocytogenes
}

\author{
Ashrafur Rahman \\ Oakland University, rahman2@oakland.edu \\ Ali Asgary \\ York University \\ Daniel Munther \\ Cleveland State University, d.munther@csuohio.edu \\ Aamir Fazil \\ Agence de la santé publique du Canada \\ Ben A. Smith \\ Agence de la santé publique du Canada
}

See next page for additional authors

Follow this and additional works at: https://engagedscholarship.csuohio.edu/scimath_facpub

Part of the Food Microbiology Commons, and the Mathematics Commons

How does access to this work benefit you? Let us know!

\section{Repository Citation}

Rahman, Ashrafur; Asgary, Ali; Munther, Daniel; Fazil, Aamir; Smith, Ben A.; and Wu, Jianhong, "An Agentbased Simulator for the Gastrointestinal Pathway of Listeria monocytogenes" (2020). Mathematics Faculty Publications. 322.

https://engagedscholarship.csuohio.edu/scimath_facpub/322

This Article is brought to you for free and open access by the Mathematics and Statistics Department at EngagedScholarship@CSU. It has been accepted for inclusion in Mathematics Faculty Publications by an authorized administrator of EngagedScholarship@CSU. For more information, please contact library.es@csuohio.edu. 
Authors

Ashrafur Rahman, Ali Asgary, Daniel Munther, Aamir Fazil, Ben A. Smith, and Jianhong Wu

This article is available at EngagedScholarship@CSU: https://engagedscholarship.csuohio.edu/scimath_facpub/322 


\title{
An agent-based simulator for the gastrointestinal pathway of Listeria monocytogenes
}

\author{
Ashrafur Rahman \\ Ali Asgary Daniel Munther Aamir Fazil Ben A. Smith Jianhong Wu
}

\section{A R T I C L E I N F O}

\section{Keywords:}

Foodborne pathogen

Stomach pH dynamics

Stomach emptying time

Food matrix

Pathogen survival

Individual-based model

\begin{abstract}
A B S T R A C T
We developed an agent-based gastric simulator for a human host to illustrate the within host survival mechanisms of Listeria monocytogenes. The simulator incorporates the gastric physiology and digestion processes that are critical for pathogen survival in the stomach. Mathematical formulations for the $\mathrm{pH}$ dynamics, stomach emptying time, and survival probability in the presence of gastric acid are integrated in the simulator to evaluate the portion of ingested bacteria that survives in the stomach and reaches the small intestine. The parameters are estimated using in vitro data relevant to the human stomach and L. monocytogenes. The simulator predicts that $5 \%-29 \%$ of ingested bacteria can survive a human stomach and reach the small intestine. In the absence of extensive scientific experiments, which are not feasible on the grounds of ethical and safety concerns, this simulator may provide a supplementary tool to evaluate pathogen survival and subsequent infection, especially with regards to the ingestion of small doses.
\end{abstract}

\section{Introduction}

Listeria monocytogenes has been widely studied in immunological research and public health over the nine decades since its discovery by Murray, Webb, and Swann in 1924 (Murray et al., 1926; VázquezBoland et al., 2001). Because of its high case fatality rate and implication in outbreaks of foodborne illness, the Gram positive bacterium continues to be a concern for public health and the economy (Buchanan et al., 2017; CDC, 2018; Farber et al., 1996; Foodnet, 2017; PHAC, 2018; Pouillot et al., 2016). With a $20-30 \%$ death rate and $92-99 \%$ hospitalization rate, $L$. monocytogenes ranks among the top deadly food pathogens (Buchanan et al., 2017; CDC, 2018; Mead et al., 1999). Pregnant women, elderly people and immunocompromised individuals (e.g. infected with chronic diseases) constitute more than $90 \%$ of those susceptible to L. monocytogenes infections (CDC, 2018). Understanding the key infection mechanisms of L. monocytogenes is useful for prioritizing prevention methodologies and reducing the burden on public health.

L. monocytogenes usually enters the host along with food through the mouth to the gut and intestine. From there, it can travel to the liver, spleen, brain (and to the placenta of pregnant women) through blood vessels (Lecuit et al., 2001). In addition to direct transport via the blood, they can also be transported via lymphocytes. Researchers have described various molecular mechanisms of $L$. monocytogenes including how this pathogen moves from cell-to-cell, survives and proliferates with-in cells, and escapes destruction inside phagosomes (Artis, 2008; Cossart, 2011; Vázquez-Boland et al., 2001). L. monocytogenes is a model bacteria for studying the molecular mechanisms of intracellular parasitism given its virulence factor associated with the hemolysin gene. Furthermore, L. monocytogenes studies have provided a fundamental understanding of the role of cellular immune response via activated macrophages for cell-mediated immunity and the elimination of intracellular pathogens (Artis, 2008; Vázquez-Boland et al., 2001).

On the larger scale, the impact of contamination of food with $\mathbf{L}$. monocytogenes has been studied using quantitative microbial risk assessment (QMRA) tools (Buchanan et al., 2017; Falk et al., 2016). Substantial research has been dedicated to elucidate dose-response relationships and to identify the ID50 of L. monocytogenes for various subpopulations (Buchanan et al., 2017; Farber et al., 1996; Haas et al., 1999; Pouillot et al., 2016; FAO/WHO, 2004). Taking a slightly 
different perspective, Rahman et al. recently proposed a mathematical model to describe the infection pathway (from ingestion to colonization of the small intestine) in guinea pigs (Rahman et al., 2016). This was one of the first studies to quantitatively link L. monocytogenes dose-response outcomes to the pathogen-host interaction in the gastro-intestinal path of the infected host. These studies, together with feeding trials (Farber et al., 1996; Roulo et al., 2014; Smith et al., 2008), can provide critical information for the hazard characterization stage of QMRA (Buchanan et al., 2017; Farber et al., 1996; Pouillot et al., 2016).

Molecular research in conjunction with outbreak findings can provide insights into the public health impact of listeriosis. In particular, the quantification of pathogen growth under a wide range of varying conditions relative to susceptible hosts is important for identifying the risk of infection. Understanding the with-in host growth mechanisms and pathogen-host interactions could be helpful to reduce the infection burden through risk management. The growth kinetics of L. monocytogenes have been extensively studied in multiple media with controlled environments (Blanco-Lizarazo et al., 2016; Schvartzman et al., 2014). However, the with-in host growth and host-pathogen interactions that translate to the success or failure of human infection are not yet understood. Due to the ethical concern of direct scientific experimentation on the human population, studies mostly focus on animal exposures. Given the importance of accurately quantifying infection risk and the limitations of human experimentation, we proposed an agent-based simulator that mimics the gastro-intestinal pathway of $\mathrm{L}$. monocytogenes and its survival probability with-in a human host.

Note that agent-based models consider the individual behavior and interaction of agents (e.g. bacteria, immune cells, etc.) in the environment in an independent manner. The impact of environmental stochasticity and randomness of interactions of agents allow the model to predict more realistic scenarios. As opposed to traditional statistical and equation based methods, the agent-based approach more adequately captures the complex spatio-temporal interactions of the subjects under consideration (Warrender et al., 2006). This is important for modeling pathogen dynamics in the gastro-intestinal tract which is highly intricate. As pathogens move along the digestive tract they interact with a dynamic environment enriched with acid, bile, enzymes, microbes and immune cells (Ohland and Jobin, 2015; Schulze, 2006; Soybel, 2005). Considering such environmental factors, pathogens may adopt multiple evasion strategies to survive in the host. Their survival as well as their potential to cause subsequent infection depend on the multiple interactions of the pathogen with the host's agents. In particular, we foresee the developed agent-based simulator as playing an important role in scenario analysis regarding the consumption of low pathogen doses along with the effects of repeated doses, the distribution of pathogens within a given meal, the impact of various food matrices, etc.

To organize the manuscript, we described the stomach physiology and digestion process in Section 2. The development of an agent-based simulator for L. monocytogenes for host-pathogen interactions is described in Section 3; within this section we also defined some key functions that are integrated in the simulator; in Section 4 we illustrated the possible outcomes of the simulator and demonstrated the sensitivity and significance of key parameters. Next, in Section 5 we discussed the outcomes, outlined the applications of the simulator and identified the caveats and possible developments of the simulator. Finally, in Section 5 we highlighted some recommendations of potential experiments to fill data gaps especially in the context of development for the simulator.

\section{Physiology of the stomach and the digestion process}

\subsection{Physiology of the stomach}

The stomach is a flexible sac whose shape varies with food intake. Generally, a human stomach has a volume of about one liter which can be reduced to as little as $80 \mathrm{ml}$ at empty state (Kong and Singh, 2008;

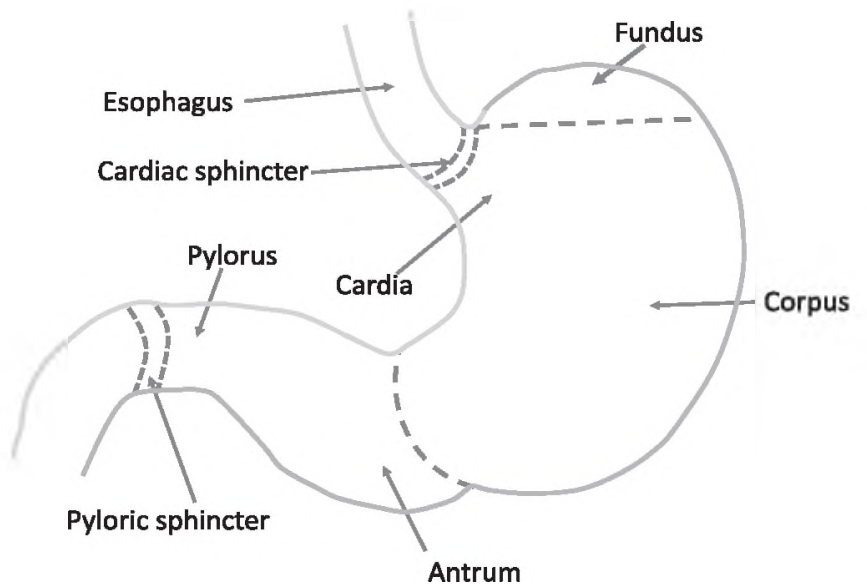

Fig. 1. A typical shape, structure and regions of a human stomach (Organ, 2019).

Mudie et al., 2014). Functionally, it can be divided into 5 major regions: the cardia, fundus, corpus, antrum, and pylorus (Fig. 1) (Soybel, 2005). Food enters into the cardia through the esophagus. The fundus, the top portion of the stomach, stores the undigested food and gases. The corpus, also known as the body, is the largest part of the stomach and contains partially digested food. The antrum contains the alkaline-secreting epithelium surface. It is a narrow passage for stomach fluid that move from the fundus to the duodenum. The pylorus is the small, end region of the stomach connected to the duodenum by the pyloric sphincter.

The stomach has three major tissue layers: beginning from the inner-side they are the mucosa, sub-mucosa and muscularis externa. The mucosa consists of the gastric glands. It is covered by a layer of columnar epithelial tissues. The gastric glands secrete gastric juices containing acid, bile salts, and digestive enzymes. The sub-mucosa consists of dense connective tissue that support the mucosa to move in a flexible manner. Blood vessels, lymphatic vessels, and nerves run through this layer. The mascularis consists of smooth muscle fibers that spiral around the tract.

The fundus relaxes as food and liquid enter the stomach to allow them into the fundic pouch. The solids continue to move along the main stream towards the pylorus. Peristaltic waves originating from the stomach wall mix the food bolus and force them towards the pylorus (Kong and Singh, 2008). The primary electrical pacemaker, which lies on the greater curvature of the stomach, initiates the waves (Soybel, 2005).

\subsection{The digestion process and gastric motility}

Food-flow in the stomach is regulated by a series of contraction and expansion processes (Schulze, 2006). As food enters into the cardia through esophagus, the gastric juices secreted from gastric glands penetrate and dilute the food bolus. The stomach acid (HCl) initiates protein digestion by activating pepsinogen that also secretes from the gastric gland. Acid enhances the absorption of minerals, calcium and iron (Howden and Hunt, 1987). In addition, stomach acid plays a crucial role in killing food pathogens from the stomach before they move to the small intestine. The proteolytic enzymes pepsin and lipase break down proteins and fats. Eventually, all food particles are broken down into small pieces so that the small intestine can absorb them or break them further into digestible molecules. During mixing and breaking, the stomach contents continue to flow towards the pylorus due to the contraction and expansion of the stomach. The pyloric sphincter relaxes and allows the resulting chyme to move into the duodenum. A human stomach takes about $1-3 \mathrm{~h}$ to complete the digestion process. 


\subsection{Simulator integration}

While the physiological process of food digestion is complex, the survival of a pathogen in the stomach is dominated by a few key factors such as the stomach $\mathrm{pH}$ and the stomach emptying time (SET) (Ohland and Jobin, 2015; Bornhorst, 2017; Rahman et al., 2016). To estimate the survival of foodborne pathogens and simulate meal intake, we only included the following characteristics: (i) meal in-take and movement, (ii) the geometric shape of the upper GI-tract, and (iii) a pathogen killing mechanism dependent on the $\mathrm{pH}$ level in the stomach. In the simulator, we outlined the geometric shape of the GI tract so that the ingested food and pathogen follow the specific route. The stomach is embedded with a motility function so that the ingested contents move through the stomach with a speed set via the SET. The gastric $\mathrm{pH}$ level which is subject to SET is monitored by a pH scale (function). Finally, the gastric component is equipped with a pathogen killing mechanism on the basis of the $\mathrm{pH}$ level.

\section{An agent based simulator (ABS) for a human stomach}

We developed an agent-based simulator for a human gastrointestinal tract to describe pathogen dynamics using AnyLogic software. The simulator is outfitted with the major aspects of the gastric component of the gastro-intestinal pathway of a human host to account for the interactions and survival mechanism of ingested pathogens. While the simulator could be adopted to other types of pathogens, the survival parameters estimated in Section 3.4 are relevant to L. monocytogenes.

The following basic assumptions for the simulator are described in this section. The simulator replicates an 'eating' event, initiated with a meal consisting of food contaminated with pathogens entering the mouth. The meal was considered to be divided into a number of portions. As a meal usually consists of different types of food, not all food portions may be contaminated. Pathogens can be present in some food portions of a meal or they can be distributed among all food portions uniformly. Each food portion contains a certain number of pathogen colony-forming units (CFUs). The food portions are consumed at an equal rate during the 'meal time' (MT). The MT could vary widely, e.g. from five minutes to an hour. After consumption, the food portions move from the mouth to the stomach through the esophagus. A food portion travels from the mouth to the stomach within 5 to $10 \mathrm{~s}$. Therefore, release of pathogens from contaminated food portions was only considered to occur in the stomach.

Pathogens move through the stomach along with the food bolus at a particular speed, described in Section 3.3. While in motion, bacteria are killed due to stomach acid as described by the survival probability (see Section 3.4). The stomach acid or $\mathrm{pH}$ level, which is highly dynamic, changes subject to the contents of the stomach, as described in Section 3.2. Within the simulator interface, the color of stomach changes from clear to light yellow for low to high $\mathrm{pH}$ values (see Section 4).

Upon survival in the stomach, pathogens move into the small intestine and continue moving along the digestive tract. A portion of pathogens will attach to the wall of the small intestine and the remainder will follow the path to the large intestine. The small intestine is a relatively favorable environment for pathogens in terms of acidity; however, pathogens are subject to attack from host immune cells. For more details regarding pathogen interaction in the small intestine see (Rahman et al., 2016) and the references therein.

\subsection{Simulator in AnyLogic}

The food portions, bacteria, and different immune cells can be treated as agents (Macal and North, 2010). However, since this paper focuses only on the stomach component, the immune cells and their behaviors will not be discussed. In terms of the current focus, the GI tract was divided into different 'areas' and 'paths'. The space markup library was used to create a 2D simulator of the GI tract based on the human digestive system (Schulze, 2006; Soybel, 2005). In particular, the geometric structure of the gastric pathway was built using splines so that pathogens are restricted to stay within the boundaries and follow the gastric route. A typical simulation begins with consumption of food portions described by an 'event' function. As food portions are consumed, they move to the stomach 'area' at equal time intervals obtained by dividing the meal duration by the number of food portions. Agents' movements were characterized using a combination of AnyLogic's pedestrian and process libraries. Agents' behaviors and interactions with each other and the environment were modeled using AnyLogic's 'state chart' functions. Upon arrival in the stomach, bacterial pathogens are released and distributed in the stomach area randomly. Bacteria spend a few minutes to several hours in the stomach following the SET as described in Section 3.3. Note that the bacteria spend time in the stomach as defined by a triangular 'delay' function. When the 'delay' is over the bacteria move from the stomach towards the small intestine. Before running the simulation, a user can define and change parameter values including: the number of food portions consumed, number of bacteria per food portion, the initial $\mathrm{pH}$ level, the maximum $\mathrm{pH}$ level, the bacterial killing rate in the stomach, and the meal portions that are contaminated by bacteria.

\section{2. $p H$ dynamics in the stomach}

Acidity is the major determining factor for pathogen survival in the stomach (Brandl et al., 2007; Koseki et al., 2011; Zhu et al., 2006). The $\mathrm{pH}$ level of the stomach varies significantly according to both the MT and SET (Russell et al., 1993). Our simulator considers the $\mathrm{pH}$ dynamics of the stomach to account for the pH-dependent pathogen killing. In an empty stomach the $\mathrm{pH}$ level typically ranges from 1.3 to 1.7 (Dressman et al., 1990; Russell et al., 1993). The pH level increases upon food consumption to reach the maximum (5.5) in about $10 \mathrm{~min}$. The $\mathrm{pH}$ level remains high for the remainder of the meal time, then declines exponentially during the SET which is about $1-3 \mathrm{~h}$ for a human host (Hellmig et al., 2006; Vasavid et al., 2014). The temporal dynamics of stomach $\mathrm{pH}$ can be described by the following function

$$
p H(t)=\left\{\begin{array}{l}
i_{p H}, t \leq 0 \\
i_{p H}+\left(\frac{\max _{p H}-i_{p H}}{\max _{p H} T}\right) t, 0<t \leq \max _{p H} T \\
\max _{p H}, \max _{p H} T<t \leq m_{T} \\
c_{0} \exp \left(-c_{1} t\right), m_{T}<t \leq e T, c_{1}=\frac{1}{e T-m T} \log \left(\frac{\max _{p H}}{e_{p H}}\right) ; \\
\quad c_{0}=\max _{p H} e^{c_{1} m_{T}} \\
e_{p H}, t>e T
\end{array}\right.
$$

Here $i_{p H}$ is the initial $\mathrm{pH}$ of the stomach at time zero or before food consumption. The $\mathrm{pH}$ increases linearly at the beginning of the meal and reaches the maximum $\mathrm{pH}$ level $\left(\max _{p H}\right)$ in $\max _{p H} T$ time units then it remains constant for the rest of the meal time $\left(m_{T}\right)$. When a meal intake is completed the $\mathrm{pH}$ level drops exponentially (Dressman et al., 1990) down to $e_{p H}$ at the end of the SET (eT), typically $2 \mathrm{~h}$ after the start of the meal. Ideally $e_{p H}$ and $i_{p H}$ are equal. All of these parameters could vary significantly from host to host. Baseline values as well as respective ranges of these parameters are listed in Table 1. Fig. 2 illustrates the $\mathrm{pH}$ dynamics in the stomach following Eq. (3.1) using baseline values from Table 1 as inputs.

\subsection{Bacterial movement through the stomach}

Pathogens are assumed to move along with food in the stomach towards the small intestine. Pathogens are killed in the stomach at dynamic rates, subject to the varying $\mathrm{pH}$ levels of the stomach. The travel and timing of food particles in the stomach is characterized by 
Table 1

The parameters of the $\mathrm{pH}$ function.

\begin{tabular}{|c|c|c|c|c|}
\hline Parameter & Description & Baseline value & Range & References \\
\hline$i_{p H}$ & Initial $\mathrm{pH}$ & 1.5 & $\lfloor 1.3,1.7\rfloor$ & (Dressman et al., 1990; Russell et al., 1993) \\
\hline $\max _{p H}$ & Maximum pH during meal & 5.5 & {$[4.5,5.5]$} & (Dressman et al., 1990; Russell et al., 1993) \\
\hline $\max _{p H} T$ & Time for $\mathrm{pH}$ to reach the maximum & $10 \mathrm{~min}$ & {$[5,15]$} & Assumption \\
\hline$e_{p H}$ & Stomach $\mathrm{pH}$ when it becomes empty & 1.5 & $\lfloor 1.3,1.7]$ & (Dressman et al., 1990; Russell et al., 1993) \\
\hline$m_{T}$ & Meal duration & $30 \mathrm{~min}$ & {$[5,60]$} & Assumption \\
\hline$e T$ & SET & $80.5 \mathrm{~min}$ & {$[40,150]$} & (Hellmig et al., 2006; Vasavid et al., 2014) \\
\hline
\end{tabular}

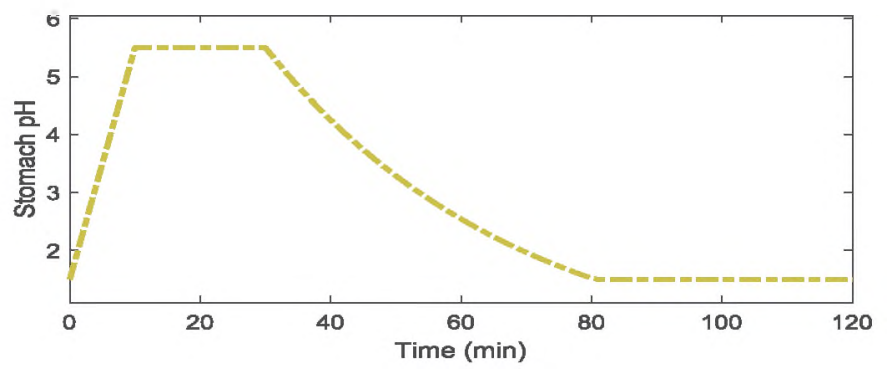

Fig. 2. Baseline stomach $\mathrm{pH}$ during food intake and digestion described by the function (3.1). The parameter values associated with this $\mathrm{pH}$ profile are given in Table 1. The stomach $\mathrm{pH}$ steadily increases to the maximum (5.5) within the first $10 \mathrm{~min}$, then remains constant until the end of the meal time $(30 \mathrm{~min}$ ) followed by an exponential decrease to the initial state (1.5) by the end of the SET

the SET. The SET depends on food matrices and host characteristics. Typically, the SET is $1-3 \mathrm{~h}$ for a human adult, with solid food taking a longer time than liquids (Hellmig et al., 2006). SETs are slightly longer for females compared to males and smokers have a significantly faster SET than non-smokers (Vasavid et al., 2014). The SET is important for the survival of pathogens in the stomach. Hellmig et al. found that the mean half SET, $S E T_{1 / 2}$, was $143.6 \mathrm{~min}$ and $80.5 \mathrm{~min}$ for solid and liquid foods, respectively (Hellmig et al., 2006). A similar study shows that the $S E T_{1 / 2}$ and percent gastric retention at $2 \mathrm{~h}$ are $68.7 \mathrm{~min}$ and $16.3 \%$, respectively (Vasavid et al., 2014). Vasavid et al. show that the stomach contents decay exponentially following a meal intake (Vasavid et al., 2014). To estimate how much time bacteria spend in the stomach we estimate the velocity function of bacteria using the SET. Given that the curvature of the upper and lower boundaries of a typical human stomach are $30 \mathrm{~cm}$ and $10 \mathrm{~cm}$ long, respectively (Ferrua and Singh, 2010), we assume that, on average, the bacteria will travel $L=20 \mathrm{~cm}$ of stomach length. Using the mean SET of 80.5 min (Hellmig et al., 2006), we estimate the speed of the bacteria in the stomach would be $v=0.25 \pm 0.06 \mathrm{~cm} / \mathrm{min}$

\subsection{Survival probability of L. monocytogenes}

The survival probability of L. monocytogenes in the stomach depends on multiple factors such as the $\mathrm{pH}$ level, the SET, the food matrix (e.g. fat content), and storage conditions of the food (storage duration, temperature, $\mathrm{pH}$ ) (Barmpalia-Davis et al., 2008, 2009). Strain specific survivability is also observed. Barmpalia-Davis et al. conducted in vitro experiments on the survival of L. monocytogenes in the gastric environment (Barmpalia-Davis et al., 2008). The storage duration in their samples varied from Day 1 to Day 82 . Since the $\mathrm{pH}$ level of their study continuously changed it is not possible to estimate the survival probability of the bacteria at a particular pH level. Koseki et al. investigated the survival probability of L. monocytogenes in a gastric fluid with different pH levels ranging from 1.2 to 2.0 (Koseki et al., 2011). They demonstrated that the survival probability increased exponentially with $\mathrm{pH}$ values. In their experiment, an initial bacterial population of $10^{6} \mathrm{cfu}$ hardly survived for $10 \mathrm{~min}$ at $\mathrm{pH}$ level 1.2 but they survived more than $4 \mathrm{~h}$ at $\mathrm{pH} 2.0$. This survival probability seems to be elevated compared to other studies (Brandl et al., 2007; Saucedo-Reyes et al., 2012; Zhu et al., 2006). On the other hand, Davis et al. found that $10^{8} \mathrm{cfu}$ of $\mathbf{L}$. monocytogenes reduced to $10^{3}$ in $30 \mathrm{~min}$ at $\mathrm{pH} 3.0$ (Davis et al., 1996). To express the survival probability of $L$. monocytogenes in terms of $\mathrm{pH}$ levels, we fit the bacterial survival data (Davis et al., 1996; Koseki et al., 2011) to an exponential function

$s_{p}(p H)=e^{-\delta(p H) t}, \delta(p H)=\delta_{2} e^{-\delta_{1} p H}$

by a nonlinear least-square curve fitting method using MATLAB's 'fmincon' subroutine (Matlab, 2019). The unit of time $t$ in the Eq. (3.2) is in minutes. From this, we estimated $\delta_{1}$ and $\delta_{2}$ to be 1.17 and 11.77 , respectively (Davis et al., 1996) or 1.30 and 3.01, respectively (Koseki et al., 2011). For more details concerning the data fitting technique, see the Appendix. We call the estimates 'high', 'low', and 'medium' (mean of high and low) estimates, respectively. The graphs of the survival functions (3.2) are shown in Fig. 3, which demonstrates the per minute survival probability of the bacteria. For example, if the probability at $\mathrm{pH} 2.0$ is 0.9 then $90 \%$ of the bacteria are expected to survive after one minute. The simulator checks the $\mathrm{pH}$ level of the stomach continuously during stomach emptying phase and kills the bacteria (agents) according to the survival probability (Eq. (3.2)). The dynamics of the survival probability relative to gastric time and $\mathrm{pH}$ are shown in Fig. 4.

\section{Gastric survival of L. monocytogenes}

This section highlights the results of numerical experiments and some applications of the ABS with regard to parameter ranges (see Tables 1 and 2) associated to L. monocytogenes. We ran the simulator to simulate how bacteria travel through the stomach with food, tracking their potential survival. Simulations of the movement components for the bacteria density in the gastro-intestinal tract without any killing mechanism are shown in Fig. 5. For the following experiments, we assumed that a meal is divided into 20 portions. We also assumed that only the first 5 food portions were contaminated and each of these portions contained 400 bacteria. (Note that this is an illustrative example and is not meant to capture all possible pathogen consumption

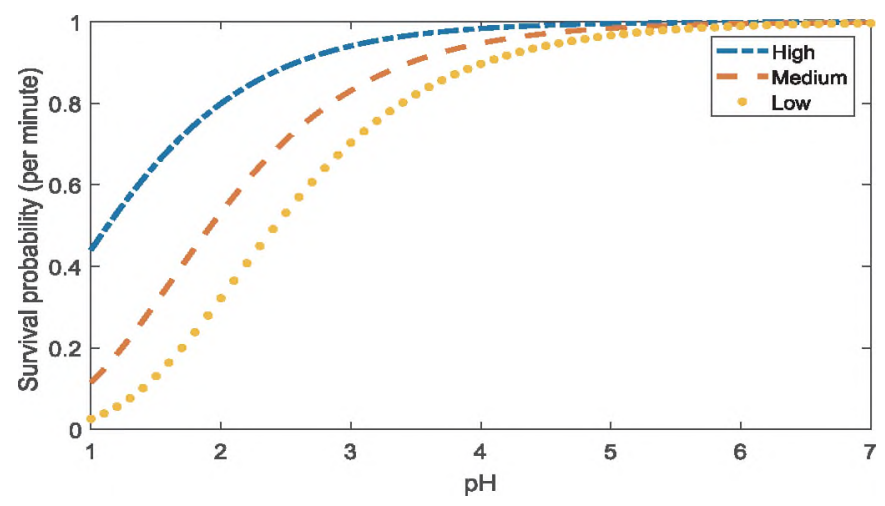

Fig. 3. Per minute survival probability (3.2) of $L$. monocytogenes at different $\mathrm{pH}$ levels. The High and Low survival probability correspond to in vitro experiments (Koseki et al., 2011) and (Davis et al., 1996), respectively. The Medium corresponds to the mean of High and Low estimates. 

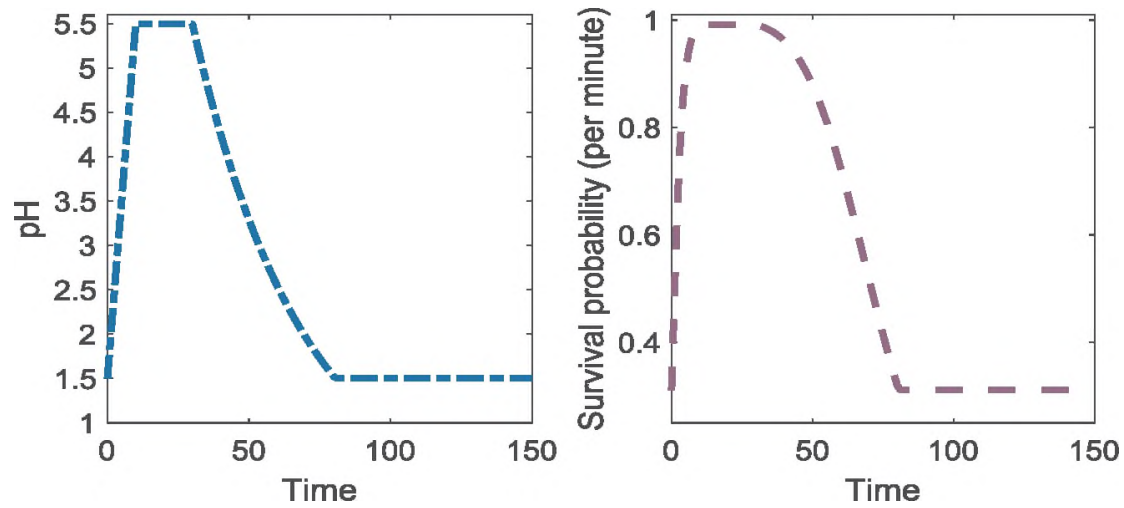

Fig. 4. Survival probability under $\mathrm{pH}$ changes. Gastric $\mathrm{pH}$ during meal and digestion (left) and the corresponding survival probability (right).

Table 2

Parameters associated with survival probability and bacterial speed in the stomach.

\begin{tabular}{lllll}
\hline Parameter & Description & Baseline value & Range & References \\
\hline$s_{p}$ & $\begin{array}{l}\text { Per-minute survival } \\
\text { probability }\end{array}$ & $e^{-7.39 e^{-1.23 r H}}$ & {$[0,1]$} & Section 3.4 \\
$v$ & $\begin{array}{l}\text { Bacterial velocity in the } \\
\text { stomach }\end{array}$ & $0.25 \mathrm{~cm} / \mathrm{min}$ & {$[0.11,4.0]$} & Section 3.3 \\
& & & & \\
\hline
\end{tabular}

scenarios during a meal. This type of scenario analysis is relegated to a future project. Please refer to the Discussion section for further details.) As the contaminated food portions reached the stomach they released the bacteria due to the stomach motility described in Section 2. The number of bacteria increased in the stomach until all the contaminated food portions (5 in this example) were consumed.

\subsection{Effects of variability in the SET}

Due to the fact that the mean SET may vary according to meal specifics (e.g. liquid vs solid) as well as host characteristics such as gender, smoker vs non-smoker, phase of menstrual cycle, post-meal activity, etc., it is important to quantify the sensitivity of pathogen survival relative to changes in this parameter (see (Vasavid et al., 2014) and references therein). Furthermore, diseases such as Gastroparesis and Parkinson's disease can alter SET (see (Bornhorst, 2017) and references therein). Given the potential for such variability, we illustrated how modification of the SET affects pathogen survival by computing the variation in the percent survival relative to ingesting pathogens contained in an example meal. In particular, we ran the simulator 50 times by randomly selecting the mean SET from a normal distribution specified by the mean and standard deviation (80.5 $\pm 22 \mathrm{~min})$ (Hellmig et al., 2006), with an initial pathogen dose of 5000 cells. Fig. 6 illustrates the result, showing that survival varies by about $17 \%$ due to the randomness of the SET

\subsection{Effects of variability in the $p H$ induced survival probability of $L$. monocytogenes}

Connected to the SET, the survival of L. monocytogenes in the stomach critically depends on the $\mathrm{pH}$ level as described in Section 3.4. A number of factors including ingested food type, use of $\mathrm{H}-2$ blockers, pathogen strain history, etc. play a role in affecting the bactericidal efficacy of a given pH level in the stomach (Martinsen et al., 2005).

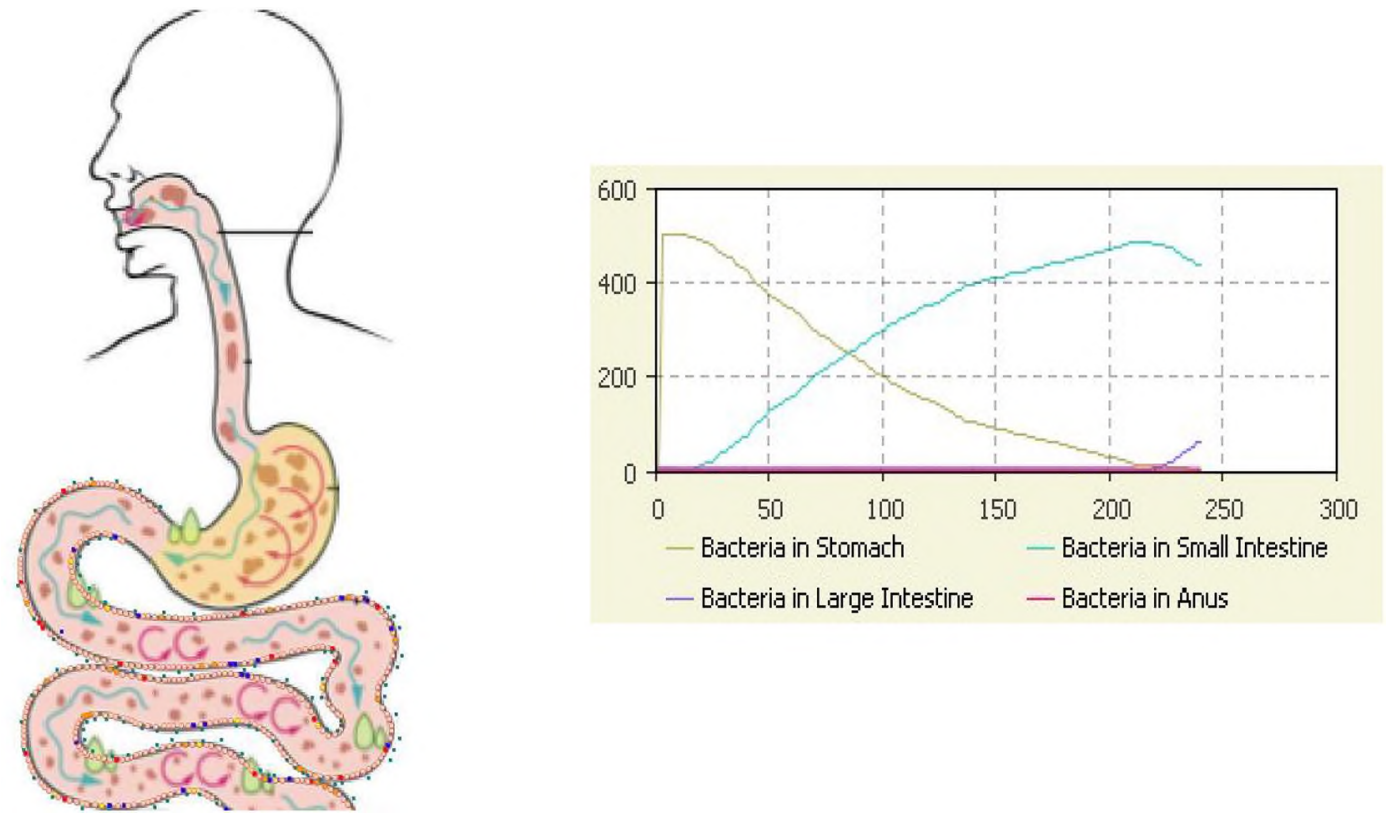

Fig. 5. Simulating only the pathogen movement through the GI-tract. The initial state of the gastrointestinal tract (left) (Biga et al., 2018). Bacterial density during the digestion phase without any killing mechanism (right). Initially, no bacteria were present in the stomach. All the bacteria are released in the stomach within a few minutes of food consumption. As the bacteria move, the number in the stomach decrease, transferring into the small intestine until the end of SET. 


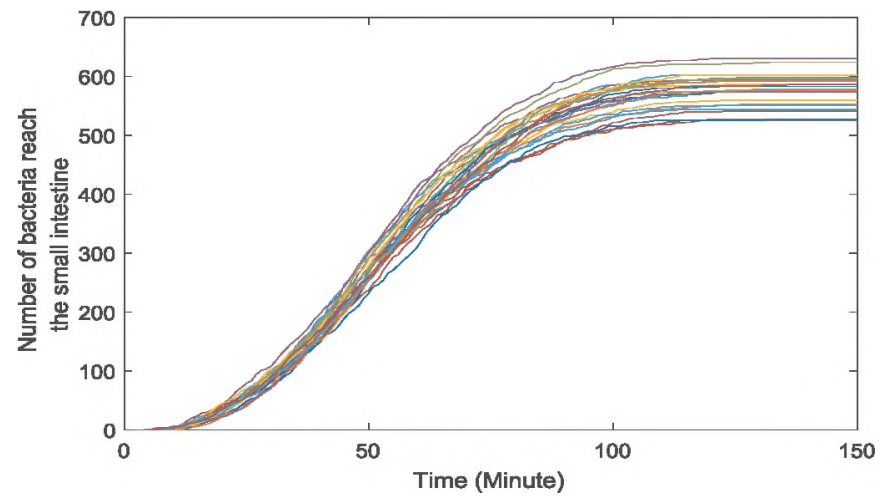

Fig. 6. Sensitivity of stomach survival with an initial dose of 5000 bacteria. The variation of survival is due to randomness of SET, sampled 50 times from the normal distribution determined by $80.5 \pm 22 \mathrm{~min}$ (Hellmig et al., 2006). The horizontal axis represents gastric time. Most of the bacteria reaches the small intestine within $2 \mathrm{~h}$ of ingestion and very few bacteria can survive in the stomach after $2 \mathrm{~h}$ due to acidity. The simulation shows that the stomach survival can vary about $17 \%$. Notice that the medium survival probability due to acid exposure (coming from Fig. 3 ) is used in these simulations.

While quantifying the variation in survival probabilities connected to such factors is not possible using in-vivo human data we utilized the results of several in-vitro studies to estimate the survival probability of L. monocytogenes subject to various $\mathrm{pH}$ levels as described in Section 3.4. To illustrate the effect of variation in the survival probability, we ran two numerical experiments, inputting 2000 and 5000 bacteria as inoculation doses. The results showed that $4.5 \pm 0.05 \%$, $10.0 \pm 0.09 \%$, and $29.0 \pm 0.13 \%$ of the ingested bacteria (associated with low, medium and, high survival probability, respectively) can survive the stomach and reach the small intestine. Note that the percentage of survival does not vary with respect to the initial values of bacteria.

\section{Discussion}

As a foodborne pathogen, $L$. monocytogenes continues to impose a substantial burden on public health. Understanding the pathogen's infection processes, which underly the dose-response relationship, is relevant to reduce this burden. While data gaps with regard to infection risk will likely persist due to ethical concerns and other limitations, "the best strategy for refining the dose-response assessment for foodborne pathogens is to advance the understanding of the underlying biology, and by doing so, refine the assumptions that underlie predictive models" (Buchanan et al., 2009). In line with this reasoning and in harmony with recent approaches for characterizing foodborne pathogen risk (for instance, the key events framework (Buchanan et al., 2009)) Rahman et al. developed mechanistic ordinary differential equation (ODE) models informed first by guinea pig data and more recently informed via outbreak data in the human context (Rahman et al., 2016; Rahman et al., 2018). The highlight of these models is the derivation of dose-response relationships in terms of parameters relating to key biological factors determined by pathogen-host interactions. In particular, the dose-response function is generated considering the variation of model parameters associated with the population's immune status and physiology and the ingested pathogen strain(s) themselves (Rahman et al., 2018). This perspective is in marked contrast with that of the classic exponential model, for instance, where each pathogen has an independent and equal probability to survive and cause infection, essentially removing variability among respective hosts and strains (Haas et al., 1999). While this assumption has a relatively minor effect in the comparative predictions of the exponential model and the model in Rahman et al. at high doses, the models' predictions significantly differ at low doses (Rahman et al., 2018).
The challenge of predicting dose-response relationships for pathogens at low exposure doses has been well-documented (e.g. (Brouwer et al., 2017; Buchanan et al., 2017) and references therein) and is aptly illustrated in a study by Holcomb et al. (1999). Comparing six dose-response models, they found significant differences (in order of magnitude) when extrapolating to low doses. Note that while the mechanistic model developed by Rahman et al. incorporates key aspects of the biology involved with the ingestion of pathogens, the model is of ODE type, implicitly assuming that a sufficiently large bacterial population can give rise to accurate predictions by only describing "averaged" pathogen-host interactions (Rahman et al., 2018). In particular, the model dynamic governing the L. monocytogenes population in the stomach was built from two main aspects: (i) the kill rate of the bacteria due to high acidity, $\delta \mathrm{cfu}\left(\mathrm{h}^{-1}\right)$ and (ii) the dispersal rate $\sigma \mathrm{cfu}\left(\mathrm{h}^{-1}\right)$ of the bacteria from the stomach to the small intestine (Rahman et al., 2018). The underlying assumption in the model form is that both these rates are exponentially distributed and only the mean value of these distributions are utilized explicitly in the model equations.

While these assumptions may be suitable for relatively large bacteria populations, in contrast with the above modeling approach, the ABS developed in this paper explicitly incorporates distributions for the killing rate of $\mathbf{L}$. monocytogenes due to acidity as well as the SET. Including this variability with respect to both these processes is an important feature of the simulator and may result in more realistic predictions for low ingested doses than using an averaged modeling approach.

Because the ABS integrates key aspects of gastric physiology and the digestive process, it can be utilized as an important tool for scenario analysis. Specifically, we designed the ABS to consider two major factors for the gastric survival of pathogens in the stomach: (1) the SET; and (2) the survival probability of pathogens at different $\mathrm{pH}$ levels. In terms of (1), the SET may vary significantly among population subgroups classified by host characteristics such as age, gender, smoker vs non-smoker, post-meal activity, health status, etc. as well as according to meal type, specified by particular food matrices (liquid vs solid) (Vasavid et al., 2014). Utilizing distributions for the SET relative to any of these factors as inputs, the ABS can be used to determine comparative risk. For example, Vasavid et al. found that the $\mathrm{SET}_{1 / 2}$ for solid food in young adults is only $68.7 \mathrm{~min}$ which is $15 \%$ lower than that of the elderly (Vasavid et al., 2014). This indicates that compared with older individuals, more bacteria are expected to survive the gastric phase of digestion in younger adults. However, due to stronger immune systems, young adults may be able to handle higher pathogen loads without developing infections. In this regard, the output of the ABS could be coupled to comparative immune response estimates with respect to age, providing insight into the risk of bacterial infection across such subgroups.

With regards to (2), the effect of $\mathrm{pH}$ on pathogen survivability may depend on the food matrix (pathogen delivery vehicle) as well as the pathogen strain. For example, during a simulated digestion study of inoculated beef frankfurters, Barmpalia-Davis et al. observed that fat content promoted L. monocytogenes survival in acidic conditions (Barmpalia-Davis et al., 2008). In addition to differing food types, variation among pathogen strains as well as strain history can impact the killing effect due to low pH (Barmpalia-Davis et al., 2008; Pettersen et al., 2019; Ramalheira et al., 2009).

To account for the potential variation in the survival probability (due to $\mathrm{pH}$ levels) of $L$. monocytogenes during digestion, the probability function (Eq. (3.2)) used in the simulator depends on parameters which were estimated from two in vitro studies (see Fig. 3 corresponding to low, medium and high survivability). Using these, the simulator predicts that $5 \%$ to $29 \%$ of the ingested bacteria can survive the stomach and reach the small intestine. This large number of stomach survival is due to higher stomach $\mathrm{pH}$ values maintained during the food intake. A significant number of ingested bacteria escape the stomach acidity before the $\mathrm{pH}$ values drops to a lethal level. Some in-vitro (lab 
simulation) studies support this result (Barmpalia-Davis et al., 2008). However, an in-vivo study involving mice speculates up to $99 \%$ of inoculated bacterial death in the stomach (Brandl et al., 2007). With the evidence of small fractions of ingested bacteria found in the small intestine (for instance, in guinea pig models) (MacDonald and Carter, 1980; Melton-Witt et al., 2012), it is suggested that the majority of the inoculum are killed in the stomach due to the bactericidal effect. However, it is unclear whether the bacteria in those studies were killed in the stomach or in the small intestine. We suspect that a significant portion of the inoculum could have also been killed in the small intestine prior to sampling and counting occurred in those studies (MacDonald and Carter, 1980; Melton-Witt et al., 2012).

In line with these ideas, it is important to mention that the ABS does not distinguish between viable and injured L. monocytogenes cells. Many researchers have demonstrated that exposure of L. monocytogenes to potentially lethal $\mathrm{pH}$ environments typically involves a two-step process where cells are initially physiologically "injured" and subsequently succumb to those injuries. Until injured cells have fully recovered, they are typically more susceptible to other stress and generally have decreased virulence (Formato et al., 2007; Koutsoumanis and Sofos, 2004; Merrell and Camilli, 2002; Wesche et al., 2009). In terms of accurately describing the dose-response function, not considering injured cells would likely lead to an overestimate of the infection risk. In future work, we plan to augment the ABS to include viable as well as injured subpopulations.

Finally, we envision that the ABS is a key tool that can be used in concert with human gastric simulators (HGS) (see (Kong and Singh, 2010) and references therein), enabling efficient scenario analysis with regards to time and money. For instance, a HGS can be used to specify parameter distributions connected to the $\mathrm{pH}$ induced kill rate relative to a particular food matrix and bacterial strain. This parameter information can then be utilized in the ABS to examine how multiple factors such as repeated doses, the distribution of pathogens in food consumed, and a variety of host characteristics contribute to the survivability of $\mathbf{L}$. monocytogenes during the gastric phase. Moreover, given such distributions of the parameters, the ABS can be run stochastically to account for individual and population level variability. As food digestion is a complex process, quantifying this variability would be an important step towards a better understanding of pathogen survival and subsequent infection within a host. Combined with stochastic simulations, this information may provide more realistic outcomes to inform dose-response models.

\section{Acknowledgments}

Daniel Munther acknowledges support from Cleveland State University startup funding (STARTUP42). Jianhong Wu's research has been funded by the Natural Sciences and Engineering Research Council of Canada and by the Canada Research Chairs program. His research is also supported by the Advanced Disaster, Emergency and Rapid Response Simulations (ADERSIM) Initiative funded by the Ontario Government.

\section{Appendix A}

\section{A.1. Data fitting and estimation of survival probability}

We estimated the parameters $\delta_{1}$ and $\delta_{2}$ of the survival probability function

$s_{p}(p H, t)=e^{-\delta(p H) t}, \delta(p H)=\delta_{2} e^{-\delta_{1} p H}$

from two published data sources (Davis et al., 1996; Koseki et al., 2011). To estimate the parameters we used the nonlinear least-square curve fitting method and Matlab's 'fmincon' subroutine (Matlab, 2019). More precisely, we minimize the error function

$E=\operatorname{nom}(M(p H, T)-\widehat{M}(p H, T))$

where $M(p H, T)=x_{0} s_{p}(p H, T)$, for $p H=1.2,1.4, \ldots, 3 ; T=0,5,25,50,100,150,200 ; x_{0}=10^{6}$ is the initial bacteria and $\widehat{M}(p H, T)$ is the corresponding data. Here the 'norm' is an $l_{2}$ matrix norm.

The bounds of $\delta_{1}$ and $\delta_{2}$ were given as $[0,15]$ and [1,15], respectively.
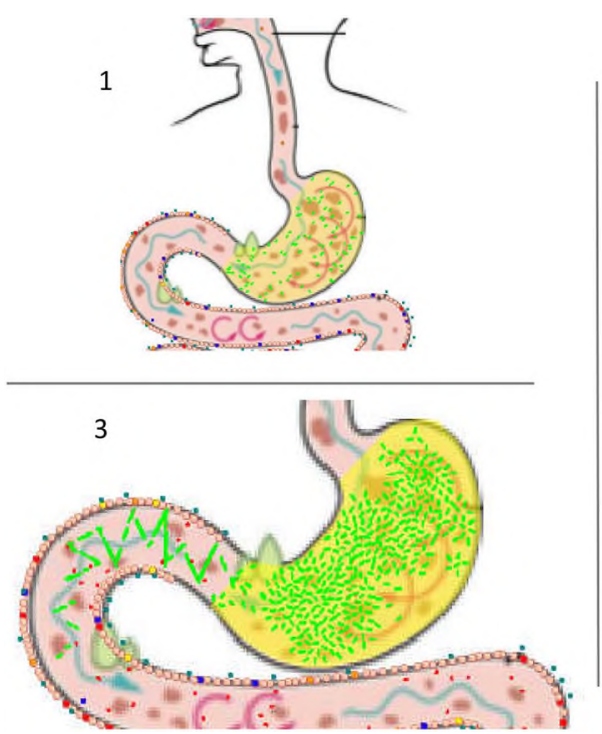

2

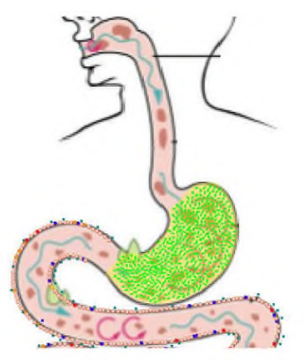

4

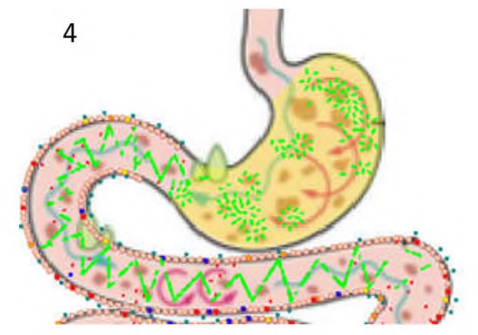

Fig. 7. Simulation of pathogen dynamics in the stomach (1-37 min). Bacteria (green) traveled through the mouth with food items (brown) into the stomach. (1) stomach bacteria after 1 min of food intake; (2) after $3 \mathrm{~min}$ the number of bacteria increased as new bacteria arrive in the stomach; (3) after $5 \mathrm{~min}$, bacteria started escaping the stomach; (4) after $37 \mathrm{~min}$ some bacteria escaped to the small intestine. (For interpretation of the references to color in this figure legend, the reader is referred to the web version of this article.) 

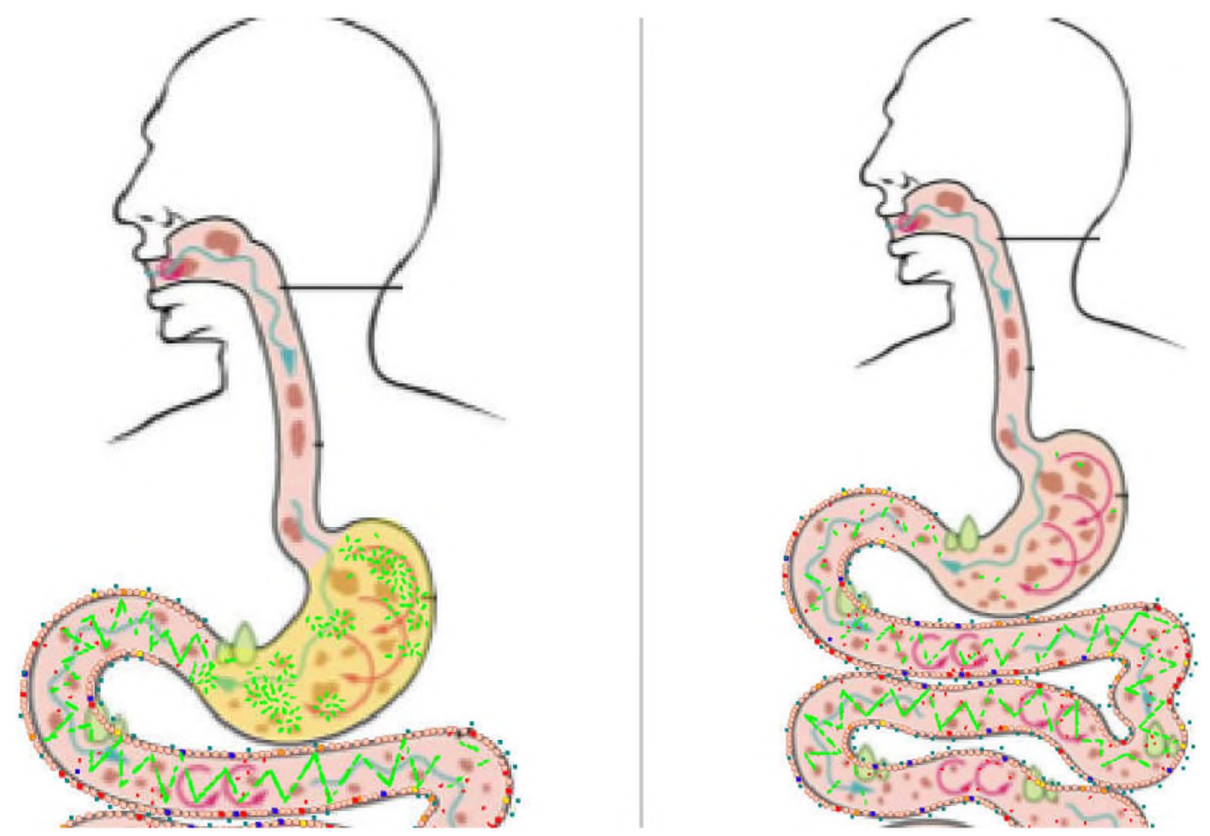

Fig. 8. Simulation of pathogen dynamics in the stomach (37-165 min). (Left) $37 \mathrm{~min}$ after bacteria entered the stomach; (Right) $165 \mathrm{~min}$ after food intake. Only a few bacteria are left in the stomach, but many of them escaped to the small intestine and followed the digestive path.

\section{A.2. Simulation process}

Figs. 7 and 8 depict sequential snapshots of the simulation process with the pH killing mechanism engaged. Fig. 7 shows the first 37 min of the digestion process followed by Fig. 8 which shows the latter phase (37-165 min) of digestion in the stomach. In these simulations the magnified view of bacteria are shown in green color. Also, note that in these figures the stomach changes from clear to a yellowish color as the pH increases due to food intake and after sufficient time returns to clear. As the simulation shows (e.g. Fig. 7), the bacteria move along the stomach with food particles towards the small intestine. The killing mechanism in the simulator is performed by removing the bacterial pathogens from the stomach phase at a probability described in Section 3.4. At the end of the stomach emptying phase the bacteria are either killed or move into the small intestine.

\section{References}

Artis, D., 2008. Epithelial-cell recognition of commensal bacteria and maintenance of immune homeostasis in the gut. Nat. rev. Immun. 8, 411-420.

Barmpalia-Davis, 1.M., Geornaras, 1., Kendall, P.A., Sofos, J.N., 2008. Survival of Listeria monocytogenes in a simulated dynamic gastrointestinal model during storage of inoculated bologna and salami slices in vacuum packages. J. Food Protec. 71, 2014-2023.

Barmpalia-Davis, I.M., Geornaras, I., Kendall, P.A., Sofos, J.N., 2009. Effect of fat content on survival of Listeria monocytogenes during simulated digestion of inoculated beef frankfurters stored at $7^{\circ} \mathrm{C}$. Food Microbiol. 26, 483-490.

Biga, L.M., Dawson, S., Harwell, A., Hopkins, R., Kaufmann, J., LeMaster, M., Matern, P., Morrison-Graham, K., Quick, D., Runyeon, J., 2018. Anatomy and physiology. https://open.oregonstate.education/aandp/chapter/23-2-digestive-systemprocesses-and-regulation/, Accessed date: 18 October 2019.

Blanco-Lizarazo, C.M., Sotelo-Díaz, I., Llorente-Bousquets, A., 2016. In vitro modelling of simultaneous interactions of Listeria monocytogenes, Lactobacillus sakei, and Staphylococcus carnosus. Food Sci. Biotec. 25, 341-348.

Bornhorst, G.M., 2017. Gastric mixing during food digestion: mechanisms and applications. Ann. Rev. Food Sci. Tech. 8, 523-542.

Brandl, K., Plitas, G., Schnabl, B., DeMatteo, R.P., Pamer, E.G., 2007. MyD88-mediated signals induce the bactericidal lectin RegIII $\gamma$ and protect mice against intestinal Listeria monocytogenes infection. J. Exper. Med. 204, 1891-1900.

Brouwer, A.F., Weir, M.H., Eisenberg, M.C., Meza, R., Eisenberg, J.N., 2017. Dose-re sponse relationships for environmentally mediated infectious disease transmission models. PLoS Comp. Biol. 13, 1-28.

Buchanan, R.L., Havelaar, A.H., Smith, M.A., Whiting, R.C., Julien, E., 2009. The key events dose-response framework: its potential for application to foodborne pathogenic microorganisms. Crit. Rev. Food Sci. Nutr. 49, 718-728.

Buchanan, R.L., Gorris, L.G.M., Hayman, M.M., Jackson, T.C., Whiting, R.C., 2017. A review of Listeria monocytogenes: an update on outbreaks, virulence, dose-response, ecology, and risk assessments. Food Control 75, 1-13.

CDC, 2018. Listeria outbreaks. Centers for disease control and prevention. https://www. cdc.gov/listeria/outbreaks/index.html, Accessed date: 16 May 2018.

Cossart, P., 2011. Illuminating the landscape of host-pathogen interactions with the bacterium Listeria monocytogenes. Proc. Natl. Acad. Sci. U. S. A. 108, 19484-19491.

Davis, M.J., Coote, P.J., Byrne, C.P.O., 1996. Acid tolerance in Listeria Monocytogenes: the adaptive acid tolerance response (ATR) and growth-phase- dependent acid resistance. Microbiol 142, 2975-2982.

Dressman, J.B., Berardi, R.R., Dermentzoglou, L.C., Russell, T.L., Schmaltz, S.P., Barnett, J.L., Jarvenpaa, K.M., 1990. Upper gastrointestinal (GI) pH in young, healthy men and women. Pharm. Res. 7, 756-761.

Falk, L.E., Fader, K.A., Cui, D.S., Totton, S.C., Fazil, A.M., Lammerding, A.M., Smith, B.A., 2016. Comparing listeriosis risks in at-risk populations using a user-friendly quantitative microbial risk assessment tool and epidemiological data. Epid. Infec. 144, $2743-2758$.

FAO/WHO, 2004. Risk Assessment of Listeria monocytogenes in Ready-To-Lat Foods, Technical Report. Food Safety Department, World Health Organization, Geneva. www, fao.org/3/a-y5394e.pdf, Accessed date: 16 May 2018.

Farber, J.M., Ross, W.H., Harwig, J., 1996. Health risk assessment of Listeria monocytogenes in Canada. Int. J.Food Microbiol. 30, 145-156.

Ferrua, M.J., Singh, R.P., 2010. Modeling the fluid dynamics in a human stomach to gain insight of food digestion. J. Food Sci. 75, 151-162.

Foodnet, 2017. National enteric disease surveillance: the Listeria initiative, https:www. cdc.gov/listeria/pdf/ListerialnitiativeOverview_508.pdf, accessed May 18, 2018.

Formato, G., Geornaras, I., Barmpalia, I.M., Skandamis, P.N., Belk, K.E. Scanga, J.A. Kendall, P.A., Smith, G.C., Sofos, J.N., 2007. Effect of acid adaptation on growth during storage at $10^{\circ} \mathrm{C}$ and resistance to simulated gastric fluid of Listeria monocytogenes inoculated onto bologna formulated with or without antimicrobials. J. Food Protec. 70, 65-69.

Haas, C.N., Thayyar-Madabushi, A., Rose, J.B., Gerba, C.P., 1999. Development and validation of dose-response relationship for Listeria monocytogenes. Quant. Microbiol 1 $89-102$.

Hellmig, S., Schoning, F.V., Gadow, C., Katsoulis, S., Hedderich, J., Folsch, U.R., Stüber. E., 2006. Gastric emptying time of fluids and solids in healthy subjects determined by $13 \mathrm{C}$ breath tests: influence of age, sex and body mass index. Gastroent 21 , $1832-1838$.

Holcomb, D.L., Smith, M.A., Ware, G.O., Hung, Y.C., Brackett, R.E., Doyle, M.P., 1999. Comparison of six dose-response models for use with food-borne pathogens. Risk Anal. 19, 1091-1100.

Howden, G.W., Hunt, R.H., 1987. Relationship between gastric secretion and infection. Gut $28,96-107$.

Kong, F., Singh, R.P., 2008. Disintegration of solid foods in human stomach. J. Food Sci. $73,67-80$.

Kong, F., Singh, R.P., 2010. A human gastric simulator (HGS) to study food digestion in 
human stomach. J. Food Sci. 75, E627-E635.

Koseki, S., Mizuno, Y., Sotome, 1., 2011. Modeling of pathogen survival during simulated gastric digestion. Appl. Environ. Microbiol. 77, 1021-1032.

Koutsoumanis, K.P., Sofos, J.N., 2004. Comparative acid stress response of Listeria monocytogenes, Escherichia coli 0157: $\mathrm{H7}$ and Salmonella typhimurium after habituation at different $\mathrm{pH}$ conditions. Letters App. Microbiol. 38, 321-326.

Lecuit, M., Vandormael-Pournin, S., Lefort, J., Huerre, M., Gounon, P., Dupuy, C., Babinet, C., Cossart, P., 2001. A transgenic model for listeriosis: role of internalin in crossing the intestinal barrier. Science 292, 1722-1725.

Macal, C.M., North, M.J., 2010. Tutorial on agent-based modelling and simulation. J. Simul. 4, 151-162.

MacDonald, T.T., Carter, P.B., 1980. Cell-mediated-immunity to intestinal infection. Infect. Immun 28, 516-523.

Martinsen, T.C., Bergh, K., Waldum, H.L., 2005. Gastric juice: a barrier against infectious diseases. Basic Clin. Pharmacol Toxicol. 96, 94-102.

Matlab, 2019. Mathlab computer programming. https:/ www.mathworks.com/products/ matlab.html, Accessed date: 18 June 2019.

Mead, P., Slutsker, L., Dietz, V., McCaig, L., Bresee, J., Shapiro, C., Griffin, P., Tauxe, R., 1999. Food related illness and death in the United States. Emer. Infect. Dis. 5, $607-625$.

Melton-Witt, J.A., Rafelski, S.M., Portnoy, D.A., Bakardjiev, A.I., 2012. Oral infection with signature-tagged Listeria monocytogenes reveals organ-specific growth and dissemination routes in Guinea pigs. Infect. Immun. 80, 720-732

Merrell, D.S., Camilli, A., 2002. Acid tolerance of gastrointestinal pathogens. Current Opin. Microb. 5, 51-55.

Mudie, D.M., Murray, K., Hoad, C.L., Pritchard, S.E., Garnett, M.C., Amidon, G.L., Gowland, P.A., Spiller, R.C., Amidon, G.E., Marciani, L., 2014. Quantification of gastrointestinal liquid volumes and distribution following a $240 \mathrm{ml}$ dose of water in the fasted state. Mol. Pharm. 11, 3039-3047.

Murray, E.G.D. Webb, R.A. Swann, M.B.R, 1926. A disease of rabbits characterised by a large mononuclear leucocytosis, caused by a hitherto undescribed bacillus Bacterium monocytogenes (n.sp.). J. Pathol. Bact 29, 407-439.

Ohland, G.L., Jobin, C., 2015. Microbial activities and intestinal homeostasis: a delicate balance between health and disease. C.M.G.H. 1, 28-40.

Organ, 2018. Organs of the body. https://www. organsofthebody.com/, Accessed date: 12 July 2018

Pettersen, K.S., Skjerdal, T., Wasteson, Y., Lindback, T., Vegarud, G., Comi, I., Aspholm, M., 2019. Survival of Listeria monocytogenes during in vitro gastrointestinal digestion after exposure to 5 and $0.5 \%$ sodium chloride. Food Microbiol. 77, 78-84.

PHAC, 2018. Public health notices. https://www.canada.ca/en/public-health/services/ public-health-notices.html, Accessed date: 16 May 2018.

Pouillot, R., Klontz, K.C., Chen, Y., Burall, L.S., Macarisin, D., Doyle, M., Bally, K.M., Strain, E., Datta, A.R., Hammack, T.S., Van Doren, J.M., 2016. Infectious dose of Listeria monocytogenes in outbreak linked to ice cream, United States, 2015. Emer. Infec. Dis. 22, 2113-2119.

Rahman, A., Munther, D., Fazil, A., Smith, B., Wu, J., 2016. Unraveling the dose-response purzle of L. monocytogenes: a mechanistic approach. Infect. Dis. Model. 1, 101-114. ahman, A., Munther, D., Fazil, A., Smith, B., Wu, J., 2018. Advancing risk assessment mechanistic dose-response modelling of Listeria monocytogenes infection in human populations. R. Soc. Open Sci. 5, 180343.

Ramalheira, R., Almeida, M., Azeredo, J., BrandĀfo, T.R., Almeida, G., Silva, J., Teixeira, P., 2009. Survival of clinical and food isolates of Listeria Monocytogenes through simulated gastrointestinal tract conditions. Foodborne Pathog. Dis. 7, 121-128.

Roulo, R.M., Fishburn, J.D., Amosu, M., Etchison, A.R., Smith, M.A., 2014. Dose response of Listeria monocytogenes invasion, fetal morbidity, and fetal mortality after oral challenge in pregnant and nonpregnant mongolian gerbils. Infect. Immun. 82 , 4834-4841.

Russell, T.L., Berardi, R.R., Barnett, J.L., Dermentzoglou, L.G., Jarvenpaa, K.M., Schmaltz, S.P., Dressman, J.B., 1993. Upper gastrointestinal pH in seventy-nine healthy, elderly North American men and women. Pharm. Res. 10, 187-196.

Saucedo-Reyes, D., Carrillo-Salazar, J.A., Reyes-Santamaría, M.I., Saucedo-Veloz, C., 2012. Effect of pH and storage conditions on Listeria monocytogenes growth inoculated into sapote mamey (Pouteria sapota (Jacq) H.E. Moore \& Stearn) pulp. Food Control $28,110-117$.

Schulze, K., 2006. Imaging and modelling of digestion in the stomach and the duodenum. Neurogast. Motil. 18, 172-183.

Schvartzman, M.S., Gonzalez-Barron, U., Butler, F., Jordan, K., 2014. Modeling the growth of Listeria monocytogenes on the surface of smear- or mold-ripened cheese. Front. Cell. Infec. Microbiol. 4, 1-9.

Smith, M.A., Takeuchi, K., Anderson, G., Ware, G.O., McClure, H.M., Ray- bourne, R.B., Mytle, N., Doyle, M.P., 2008. Dose-response model for Listeria monocytogenes-induced stillbirths in nonhuman primates. Infect. Immun. 76, 726-731.

Soybel, D.I., 2005. Anatomy and physiology of the stomach. Surg. Clin. North Amer. 85, 875-894.

Vasavid, P., Chaiwatanarat, T., Pusuwan, P., Sritara, C., Roysri, K., Namwong- prom, S., Kuanrakcharoen, P., Premprabha, T., Chunlertrith, K., Thongsawat, S., Sirinthornpunya, S., Ovartlarnporn, B., Kachintorn, U., Leelakusolvong, S., Kositchaiwat, C., Chakkaphak, S., Gonlachanvit, S., 2014. Normal solid gastric emptying values measured by scintigraphy using Asian-style meal: a multicenter study in healthy volunteers. J. Neuro. Mot. 20,371-378.

Vázquez-Boland, J., Kuhn, M., Berche, P., Chakraborty, T., Domi, G., Gonzálezzorn, B., Wehland, J., 2001. Listeria pathogenesis and molecular virulence determinants. Clin. Microbiol. Rev. 14, 584-640.

Warrender, C., Forrest, S., Koster, F., 2006. Modeling intercellular interactions in early Mycobacterium infection. Bull. Math. Biol. 68, 2233-2261.

Wesche, A.M., Gurtler, J.B., Marks, B.P., Ryser, E.T., 2009. Stress, sublethal injury, resuscitation, and virulence of bacterial foodborne pathogens. J. Food Protec. 72. 1121-1138.

Zhu, H., Hart, C.A., Sales, D., Roberts, N.B., 2006. Bacterial killing in gastric juice - effect of $\mathrm{pH}$ and pepsin on Escherichia coli and Helicobacter pylori. J. Med. Microbiol. 55. $1265-1270$.

Post-print standardized by MSL Academic Endeavors, the imprint of the Michael Schwartz Library at Cleveland State University, 2020 